\section{Determinants of scabies out- break in Takusa district of Amhara Region, Northwest Ethiopia}

\author{
Etsehiwot Debe Worku, ${ }^{1}$ \\ Mulusew Andualem Asemahagn, ${ }^{2}$ \\ Melese Linger Endalifer ${ }^{3}$ \\ ${ }^{1}$ Public health emergency management \\ officer, North Showa Zone, Amhara \\ Regional Health Bureau; ${ }^{2}$ School of \\ Public Health, College of Medicine and \\ Health Sciences, Bahir Dar University, \\ Bahir Dar; ${ }^{3}$ College of Health Science, \\ Woldia University, Woldia, Ethiopia
}

\section{Abstract \\ Background: Human scabies is a highly contagious human dermatitis disease. As indicated by the national and regional reports, the epidemic of scabies became a major public health problem in Ethiopia since 2015.}

Objective: To identify the determinant factors of scabies outbreak in Takusa district, Northwest Ethiopia, 2017.

Methods: A community based unmatched case-control study among 188 participants (63 cases and 125 controls) was conducted in Takusa district from September to October 2017. Data were collected using a pretested structured questionnaire. Multivariable logistic regression analysis was computed using SPSS version 22 to identify factors associated with scabies. Odds ratio at $95 \% \mathrm{CI}$ and p-value less than 0.05 were used to describe the strength of the association and statistical significance.

Results: The median age of cases was 20 years (ranges1-61). Presence of person with itching in the family $(\mathrm{AOR}=7.7,95 \%$ CI:1.9-30.5), sleeping with scabies patient (AOR=3.99, 95\% CI:1.37-11.7), travel to scabies epidemic area in the last six weeks (AOR=3.79, 95\%CI:1.28-11.1) and infrequent use of detergent for showering $(\mathrm{AOR}=4.85 ; 95 \% \mathrm{CI}: 1.3-17.9))$ were found to be determinant factors of scabies outbreak.

Conclusion: Frequent contact with people who develop scabies at home, not using detergents for washing, and mobility of people from non-epidemic to the epidemic areas were determinant factors. Giving special emphasis on regular awareness creation to the rural community is important to prevent scabies outbreak.

\section{Introduction}

Human scabies is an ectoparasitic infestation of human skin caused by a microscopic female mite known as Sarcoptes scabiei variety hominis. ${ }^{1}$ Scabies occurs when the pregnant female mite burrows into superficial layers of the skin, forming a slightly elevated narrow tunnel where it deposits eggs and feces. The mite requires human skin to complete its life cycle and is unable to survive the host at room temperature for more than 2-3 days. ${ }^{2}$

Scabies occurs worldwide and its global prevalence is estimated to be about 300 million cases per year. ${ }^{1,3}$

The prevalence and complications of scabies make it a significant public health problem in the developing world, with a disproportionate burden among children living in poor, and overcrowded tropical areas. $^{4,5}$ As evidenced from a narrative review the distribution of Scabies at the population level in the developing countries lies between $0.4-31 \%{ }^{6}$

Countries in the tropical climate zone accounted for $25 \%$ of the global scabies incidence. It reached $50 \%$ in some communities of the South Pacific and Northern Australia where poverty and overcrowding are the main risk factors. ${ }^{7}$

Multiple factors like overcrowding, ${ }^{6}$ poor public health education, ${ }^{1}$ overcrowded sleeping space, sharing of clothes, sharing of towels,${ }^{8}$ improper personal hygiene practices, ${ }^{4,6,9}$ family size, ${ }^{10,11}$ dementia, ${ }^{12}$ age below 15 years, homes affected by flooding. ${ }^{13}$ and traveling from non-endemic to scabies endemic areas, ${ }^{3,5,7}$ residing in rural areas, family history of scabies, educational status, household density, the existence of livestock or rodents at home, seasonal conditions, occupation, type of building for living, family history of itchy rash, poverty, low socioeconomic status and presence of head lice were identified as determinant factors in the previous studies from different parts of the world. $3,13-17$

According to a study conducted in Pakistan, the prevalence of scabies was $9.13 \%$ and it varies among sex, socioeconomic status, and living conditions (household standards). ${ }^{18}$ Similarly, the prevalence of scabies was $9.3 \%$ and $11 \%$ in Northwest and southern Ethiopia. ${ }^{13,19}$

Ethiopia is one of the countries affected by the scabies outbreaks, which is aggravated by climate change, Latino. The distribution of scabies outbreak varied across regions and districts of Ethiopia, with the highest magnitude to places with poor access to water sources, infrastructures, and food security. ${ }^{20}$ Based on the office report from Takusa district, Northwest Ethiopia,
Correspondence: Melese Linger Endalifer, College of Health Science, Woldia University, Woldia, Ethiopia.

Tel.:+251927690730

E-mail: melselinger@gmail.com

Key words: Determinant factors, Ethiopia, Scabies, Outbreak, Takusa district.

Acknowledgments: We would like to forward our deepest gratitude to the school of Public Health, Bahir Dar University, Amhara Regional Health Bureau, data collectors, and study participants for the valuable help they did during the study period.

Contributions: EDW: designed research proposal, supervised data collection, analyzed data, wrote, edited approved the manuscript. MAA: participated in the design of the study, performed the statistical analysis, reviewed, edited, and approved the proposal and manuscript. MLE: participated in drafting the manuscript, critical revision of the manuscript, and final approval.

Conflict of interest: The authors declare no potential conflict of interest.

Funding: None.

Consent for publication: Not applicable.

Availability of data and materials: can be accessed from the corresponding author upon reasonable request.

Received for publication: 26 December 2019. Revision received: 9 July 2020.

Accepted for publication: 21 Ovtober 2020.

This work is licensed under a Creative Commons Attribution NonCommercial 4.0 License (CC BY-NC 4.0).

${ }^{(C)}$ Copyright: the Author(s),2020

Licensee PAGEPress, Italy

Journal of Public Health in Africa 2020; 11:1325 doi:10.4081/jphia.2020.1325

there were about $13975(8.9 \%)$ scabies cases from a total population of 147,626 . There were 7229 (51.7\%) male cases; while pregnant and lactating mothers comprised 788 $(6 \%)$ of all cases in the district. The distribution of the scabies incidence was varied across kebeles, smallest administrative units in the district, where Dinblagsa, Quardiba, and Konta kebeles accounted for $39.5 \%, 36.3 \%$, and $31.4 \%$ of the scabies incidence, respectively. The incidence of scabies is high in the district. As a result, we intended to identify the determinant factors of scabies there. This study will be important to take evidence-based interventions to 
prevent scabies outbreak and its burden.

\section{Methods and materials}

\section{Ethical considerations}

The study was conducted as per the Helsinki Declaration for biomedical research. The ethical review committee of Bahir Dar University has reviewed and approved the research protocol and gave a supporting letter together with the Amhara Regional Health Bureau to proceed with the research work. Study participants were well informed about the purpose of the study, data collection procedures, and data confidentiality issues before the actual data collection period. For study participants less than 18 years, informed consent was taken from their families and caregivers after being informed about the research. Participation was fully voluntary based including the right to withdraw from the study at any time without any preconditions. Data confidentiality was assured by removing any personal identifiers (using codes) and using data anonymity. Critically ill scabies cases were referred to the nearby health center for healthcare services. On the other hand, to non-critical cases, education was given to prevent themselves and the community from further scabies infections.

\section{Study area and period}

Unmatched community-based casecontrol study design was used in Takusa District, Northwest Ethiopia from September to October 2017. The District is found 90-kilo meters away from Gondar town, a capital town of North Gondar zone. The district has a total population of 147,626 in 2017/2018 with 5.5\% urban residences. There were about 28 health posts, five health centers, and one primary hospital providing health care services in the district.

\section{Source and study population}

People living in the Takusa district for six months and above were considered as source population and people living in the selected kebeles of the Takusa district were the study population to this study.

\section{Sample size determination and sam- pling technique}

The sample size of the study was calculated using Epi Info TM 7 (Centers for Disease Control, Atlanta, GA, USA) using the scabies proportion $(26.56 \%)$ and odds ratio of factors to scabies $(\mathrm{AOR}=2.76)$ from the previous studies. ${ }^{3}$ Thus, the total sample size was 188 (63 Cases and 125 Controls).
Three kebeles, namely: Dinblagsa, Quardiba, and Konta were selected randomly from 16 kebeles reporting scabies case. Due to time and resource constraints and the district is remote. we limit the number of studied kebeles to three. Then, the cases were randomly selected from the line list and two controls were selected through a simple random technique.

\section{Data collection tools and techniques}

The data were collected at the household level through an interviewer-administered questionnaire. It was based on evidence about cases collected from the health posts (least primary health care facilities) and health centers that scabies cases were traced to their houses. The questionnaire was developed by reviewing related literatures on scabies and scabies assessment check-list of Ethiopia. Three trained clinical nurses under the supervision of the principal investigators collected the data after getting informed consent from each study participant.

\section{Data quality assurance}

Developing the questionnaire by referring various literature, training of data collectors, regular supportive supervision of data collectors, checking data completeness and data clearance during data analysis were some of the data quality assurance activities to this study.

\section{Data processing and analysis}

Data were entered and cleaned with
Epidata version 3.1 and exported to the Statistical Package for Social Sciences (SPSS) version 22 (Chicago, IL, USA) for further data clearance and analysis. Descriptive frequency statistics (measures of central tendency, proportions, and crosstabulations were conducted to describe study participants and variables. Bivariate and multivariable logistic regression analyses were computed to identify the determinant factors of scabies. Variables having a P-Value $<0.2$ in bivariate analysis entered into the multivariable logistic regression model to control the effect of confounding variables. Finally, variables having a Pvalue $<0.05$ at $95 \% \mathrm{CI}$ were considered as determinant factors to scabies infection.

\section{Results}

\section{Descriptive-statistics}

The median age of cases was $20 \pm 16.5$ years (ranges:1-61 years).Similarly, the median ages of controls was 18 years (ranges1-70). Over half, 103 (54.7\%) of the study participants were females. The majority, $54(85.7 \%)$ of the scabies cases and $105(84 \%)$ controls were from rural areas. About $44(70 \%)$ of cases and $82(65.6 \%)$ controls lived in families that have five and above family size (Table 1).

\section{Clinical presentation of scabies}

As illustrated in Figure 1, the attack rate (AR) was also high in the age of $\geq 45$ years which was 29839 cases per 100,000 population followed by under-five children with

Table 1. Sociodemographic characteristics of the cases and controls, Takusa District, Northwest Ethiopia, 2017.

\begin{tabular}{|c|c|c|c|}
\hline Variables & & Cases, N (\%) & Control, N(\%) \\
\hline Sex & $\begin{array}{l}\text { Female } \\
\text { Male }\end{array}$ & $\begin{array}{l}30(47.6) \\
33(52.4)\end{array}$ & $\begin{array}{l}73(58.4) \\
52(41.6)\end{array}$ \\
\hline Residence & $\begin{array}{l}\text { Rural } \\
\text { Urban }\end{array}$ & $\begin{array}{c}54(85.7) \\
9(14.3)\end{array}$ & $\begin{array}{l}105(84) \\
20(16)\end{array}$ \\
\hline Occupation & $\begin{array}{l}\text { Farmer } \\
\text { Student } \\
\text { Housewife } \\
\text { Merchant } \\
\text { Not eligible }\end{array}$ & $\begin{array}{c}23(36.5) \\
20(31.7) \\
4(6.3) \\
4(6.3) \\
12(19)\end{array}$ & $\begin{array}{c}38(30.4) \\
43(34.4) \\
15(12) \\
8(6.4) \\
21(16.8)\end{array}$ \\
\hline Family size & $\begin{array}{l}<5 \\
\geq 5\end{array}$ & $\begin{array}{l}19(30) \\
44(70)\end{array}$ & $\begin{array}{l}43(34.4) \\
82(65.6)\end{array}$ \\
\hline Marital status & $\begin{array}{l}\text { Single } \\
\text { Married } \\
\text { Divorced } \\
\text { Widowed } \\
\text { Not eligible }\end{array}$ & $\begin{array}{c}17(27) \\
28(44.4) \\
0 \\
2(3.2) \\
16(25.4)\end{array}$ & $\begin{array}{c}28(22.4) \\
50(40) \\
7(5.6) \\
3(2.4) \\
37(29.6)\end{array}$ \\
\hline Educational status & $\begin{array}{l}\text { Unable to read and write } \\
\text { Primary } \\
\text { Secondary and above } \\
\text { Not eligible }\end{array}$ & $\begin{array}{c}29(46) \\
22(35) \\
2(3.2) \\
10(15.9)\end{array}$ & $\begin{array}{c}42(33.6) \\
52(41.6) \\
12(9.6) \\
19(15.2)\end{array}$ \\
\hline
\end{tabular}


AR of 10454 cases per 100,000 population (Figure 1). Over a third, 36(57.1\%) of the study participants were infected with very severe scabies rash while only two have subsided from the rash. Fifteen (24\%) of patients were unable to perform their daily routine activities due to the disease; of which, $11(73.3 \%)$ were students who dropped out of schools as a result of scabies infection.

Among the cases; $56(88.9 \%)$ of them initially presented with itching, which was intense at night. Most of the cases, $61(96.8 \%)$ had an active rash, and two $(3.2 \%)$ have no active rash. Regarding the severity of the lesions, 6 cases had mild $\leq 5$ maculopapular scabies rash, 10(15.9\%), moderate (6-10), 9(14.3\%) severely affected 11-49 lesions, and 36(57.1\%) were very severely affected by the scabies rash.

Regarding the anatomical site of the rash, $16(25.4 \%)$ of patients started the rash at their hands, $14(22.2 \%)$ at their wrist, $9(14.3 \%)$ at elbows, $6(9.5 \%)$ at the groin, $4(6.3 \%)$ at the waist line, $3(4.8 \%)$ at armpits, 1 at breast and $10(15.9 \%)$ at the other body parts (Figure 2).

About 31(49\%) cases have expanded rashes to the whole-body parts,11(17.5\%) $\geq$ six different body parts, $9(14.5 \%)$ in 4 body parts, $6(9.5 \%)$ to 3 body parts, $3(4.8 \%)$ to 2 body parts and only $3(4.8 \%)$ of patients have undistributed scabies rash until the date of the investigation. Among the total, thirty $(47.6 \%)$ scabies patients had infected lesions and $13(20.6 \%)$ of the cases had crusted lesions (a very contagious type of scabies).

\section{Determinant factors of a scabies outbreak in Takusa district}

The multivariable logistic regression analysis showed that the presence of persons with itching in the family, infrequent use of soap, sleeping with the person with active scabies case, travel to scabies epidemic area in the last six weeks, and history of scabies were determinants factors for scabies outbreak ( $p$-value $<0.05$ ) in Takusa district. The presence of anyone complaining of itching in the home increases the likely hood of being infected by scabies 7.7 times compared to people with no family member that has itching. Sleep with a person who had scabies increase the likely hood of scabies 3.9 times as compared to a person who slept alone. The odds of getting scabies infection were 4.85 times higher among participants who did not use detergents for personal hygiene frequently compared to users. Traveling to a scabies epidemic area increases the likely hood of scabies infection by 3.79 times compared to people who did not have travel history to the epidemic areas. Patients who had the previous history of scabies were 19.7 times more likely to acquire scabies infection compared to patients with had no previous scabies history (Table 2).

\section{Discussion}

Based on this study, scabies has become a public health emergency in Ethiopia. It is a public health outbreak problem in the Amhara region and its districts. The current research identifies the following determinant factors to scabies outbreak in the study area; the presence of a person with itching in the family/colleagues, sleeping with scabies cases, and infrequent use of detergent for showering, travel to scabies epidemic area and the previous history of scabies infestation were determinant factors of scabies infestation in the Takusa district (Table 2). The Attack rate was higher in the age group of $\geq 45$ years and under-five children.
The two extremities (elders and children) are indeed at the highest risk of scabies infection due to weak immunity status and unable to care for their hygiene by themselves. ${ }^{21}$ This indicates that special attention and care are needed from the families, caregivers, and the local government towards children and elders to keep them from acquiring scabies infection.

Based on this study, scabies incidence was higher in males than in females, which might be attributed to the high mobility of males and stay outdoor for longer times than females per day which might expose them to the infection. Besides, females have relatively better access to water sources than males since most of the time; females are food cookers and handlers, caregivers to children, washing clothes, and fetch water. Thus, they might have relatively better chance to hand washing and shower services. Even though the case was high in males, females were affected by very severe types of scabies rash secondary to intensive

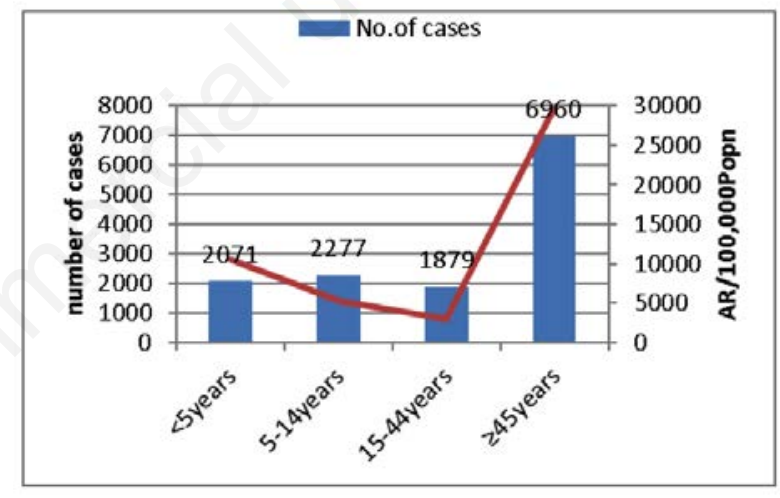

Figure 1. Distribution of scabies cases by age and AR, Takusa District, Northwest Ethiopia, 2017. AR: Attack rate.

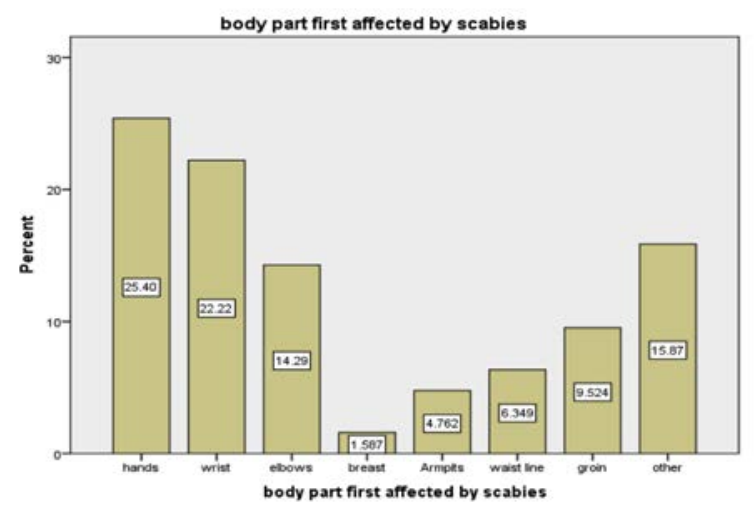

Figure 2. Presents the participant's first body part affected by the scabies infestation, Takusa District, Northwest Ethiopia, 2017. Others: mouth, legs, face. 
itching which is severe at night. This might be related to differences in the immune system, where females have relatively weaker immune systems compared to males for biological, health conditions, and pregnancy-related issues. ${ }^{18}$

According to this study, respondents who had pertaining itching in the family/colleagues were more likely to get scabies infection as compared to those who had no itching. Various study findings from west Iran, ${ }^{14}$ Pakistan, ${ }^{16}$ Northwest Ethiopia, ${ }^{19}$ and Egypt ${ }^{15}$ also reported this fact. This is because one of the transmission mechanisms of scabies to the other parts of the body and other contacts is through itching and pus discharges as a result of itching. Through itching, they will transmit infections as well as get the pathogen to themselves (reinfection) via those affected skins. ${ }^{22}$

Similarly, sleeping with a person who had active scabies infestation/skin contact were more likely to acquire scabies infection compared to the counterpart patients. This finding is also supported by studies conducted in Pakistan, ${ }^{16}$ Southern Ethiopia, ${ }^{10}$ and Gondar. ${ }^{3}$ Whereas sleeping with active scabies cases was a statistically significant factor to develop scabies infection. This might be related to the contagious nature of scabies from active cases to the people that live through skin, clothes, sleeping together and related mechanisms. ${ }^{6,22}$

Infrequent use of soap for bathing (personal hygiene) was statistically significant with scabies infection. This finding is supported by studies in West Iran $^{14}$ and Northwest Ethiopia. ${ }^{19}$ Frequent use of detergent for showering and personal hygiene is one of the effective preventive mechanisms of scabies infection. Because it is important to remove immature mites from the skin so that the number of mites reduces the likelihood of transmission. ${ }^{22}$

Likewise, traveling to the scabies epidemic areas was statistically significant with acquiring scabies infestation. This finding is in line with studies conducted elsewhere. ${ }^{3,14}$ This could be due to the contagious nature of scabies through direct and indirect contact of active cases. Thus, people who are from non-endemic areas (has no previous exposure) will get scabies infection by the microorganism easily while traveling to the endemic areas where more active cases are living.

The previous history of scabies infection was found to be a determinant factor for scabies infection. History of scabies infection was the risk factor of a severe form of scabies infection since the shorten- ing of the incubation period to secondary infections ranging 1-4 days following mite exposure. It presents with intense itching (pruritus), especially at night, and a pimplelike (papular) itchy rash.

In contrast, the family size was frequently reported as a determinant factor to scabies infection in previous studies, ${ }^{7,10,11,13}$ but in this research, it was found to be nonsignificant. Although it is not statistically significant, it is a predisposing factor to acquire scabies infection since the family size has a direct impact on access to water sources, food insecurity, poor personal and environmental hygiene, poor nutrition, and higher exposure to scabies cases due to movements for getting family income in the form of daily laborers, servants, and guards. The family size will also affect access to detergents, shower services, and clothing.

Even though the study has strengths, it has some limitations that might have little impact on the quality of study findings and discussion. For example, the cases were selected from the line list at the district level, but unknown cases were present in the community which might have an impact on the identification of potential factors. Also, the diagnosis was carried out only on a clinical basis, which may result in misclassification of cases.

Table 2. Determinant factors of a scabies outbreak among participants in Takusa district, Northwest Ethiopia, 2017.

\begin{tabular}{|c|c|c|c|c|c|c|}
\hline Variables & & Cases & Controls & COR (95\%CI) & AOR (95\%CI) & P-value \\
\hline Sex & $\begin{array}{l}\text { Female } \\
\text { Male }\end{array}$ & $\begin{array}{l}30 \\
33\end{array}$ & $\begin{array}{l}73 \\
52\end{array}$ & $\begin{array}{c}0.65(0.35-1.19) \\
1\end{array}$ & $\begin{array}{c}0.79(0.27-2.3) \\
1\end{array}$ & 0.65 \\
\hline Complaining of itching & $\begin{array}{l}\text { Yes } \\
\text { No }\end{array}$ & $\begin{array}{c}58 \\
5 \\
\end{array}$ & $\begin{array}{l}59 \\
66 \\
\end{array}$ & $\begin{array}{c}13(4.91-34.5) \\
1\end{array}$ & $\begin{array}{c}7.7(1.9-30.5) \\
1\end{array}$ & 0.003 \\
\hline Sleeping with scabies patient & $\begin{array}{l}\text { Yes } \\
\text { No }\end{array}$ & $\begin{array}{l}40 \\
23\end{array}$ & $\begin{array}{c}22 \\
103\end{array}$ & $\begin{array}{c}8.14(4.08-16.22) \\
1\end{array}$ & $\begin{array}{c}3.99(1.37-11.7) \\
1\end{array}$ & 0.01 \\
\hline Using clothes of scabies infected person & $\begin{array}{l}\text { Yes } \\
\text { No }\end{array}$ & $\begin{array}{l}27 \\
36\end{array}$ & $\begin{array}{c}15 \\
110\end{array}$ & $\begin{array}{c}5.5(2.6-11.5) \\
1\end{array}$ & $\begin{array}{c}1.64(0.37-7.2) \\
1\end{array}$ & 0.51 \\
\hline Bathing scabies patient & $\begin{array}{l}\text { Yes } \\
\text { No }\end{array}$ & $\begin{array}{l}25 \\
38\end{array}$ & $\begin{array}{c}15 \\
110\end{array}$ & $\begin{array}{c}4.63(2.2-9.7) \\
1\end{array}$ & $\begin{array}{c}2.27(0.75-6.8) \\
1\end{array}$ & 0.14 \\
\hline Share bed cloth & $\begin{array}{l}\text { Yes } \\
\text { No }\end{array}$ & $\begin{array}{l}40 \\
23\end{array}$ & $\begin{array}{c}25 \\
100\end{array}$ & $\begin{array}{c}5(2.6-9.6) \\
1\end{array}$ & $\begin{array}{c}0.93(0.23-3.9) \\
1\end{array}$ & 0.92 \\
\hline Detergent use & $\begin{array}{l}\text { Only with water } \\
\text { With soap }\end{array}$ & $\begin{array}{l}23 \\
40\end{array}$ & $\begin{array}{c}10 \\
115\end{array}$ & $\begin{array}{c}6.17(2.7-14.1) \\
1\end{array}$ & $\begin{array}{c}4.85(1.3-17.9) \\
1\end{array}$ & 0.018 \\
\hline Travel to scabies epidemic area & $\begin{array}{l}\text { Yes } \\
\text { No }\end{array}$ & $\begin{array}{l}22 \\
41\end{array}$ & $\begin{array}{c}22 \\
103\end{array}$ & $\begin{array}{c}2.4(1.196-4.734) \\
1\end{array}$ & $\begin{array}{c}3.79(1.28-11.1) \\
1\end{array}$ & 0.01 \\
\hline History of scabies & $\begin{array}{l}\text { Yes } \\
\text { No }\end{array}$ & $\begin{array}{l}13 \\
50\end{array}$ & $\begin{array}{c}10 \\
111\end{array}$ & $\begin{array}{c}3.01(1.196-4.734) \\
1\end{array}$ & $\begin{array}{c}19.8(3.04-128.8) \\
1\end{array}$ & 0.002 \\
\hline Knowledge about scabies & $\begin{array}{l}\text { Yes } \\
\text { No }\end{array}$ & $\begin{array}{l}11 \\
52\end{array}$ & $\begin{array}{l}36 \\
89\end{array}$ & $1.9(0.879-4.08)$ & $\begin{array}{c}1 \\
2.54(0.73-8.8)\end{array}$ & 0.14 \\
\hline Daily Water consumption & $\begin{array}{l}\geq 20 \text { Litter } \\
<20 \text { Litter }\end{array}$ & $\begin{array}{l}10 \\
53\end{array}$ & $\begin{array}{l}43 \\
82 \\
\end{array}$ & $\begin{array}{c}1 \\
2.68(1.2-5.7) \\
\end{array}$ & $\begin{array}{c}1 \\
0.74(0.213-2.56) \\
\end{array}$ & 0.63 \\
\hline
\end{tabular}


2015. J Biol 2017;13.

\section{Conclusions}

The present study showed that scabies is a public health concern in the Takusa district which needs informed decision to prevent scabies infection. The proportion of scabies was found to be higher among under-five children and those greater than 45 years. The presence of a person with itching in the family/colleagues, sleeping with scabies cases, infrequent use of detergent for showering, travel to scabies epidemic area and previous history of scabies infestation were determinant factors of scabies infestation in the Takusa district. Special attention to regular awareness creation among the rural communities, using prophylaxis while traveling to the epidemic areas, access and use of detergents, reducing food insecurity, care and support to elders and children, and access to water sources is important to prevent scabies infestation in the study area.

\section{References}

1. WHO. lymphatic filariasis and epidemiology of scabies. 2016. [http://www.who.int/lymphatic_filariasis/epidemiology/scabies/en/.

2. Davis CP. How Do You Get Scabies? Available from: https://www.emedicinehealth.com/how do_you_get_scabies/article_em.htm

3. Yassin ZJ, Dadi AF, Derseh BT, et al. Scabies Outbreak Investigation among "Yekolo Temaris" in Gondar Town, North Western Ethiopia, November
4. Chosidow O. Clinical practices Scabies. N Engl J Med 2006;354:1718-27.

5. Walton SF, Holt DC, Currie BJ, Kemp DJ. Scabies: new future for a neglected disease. Adv Parasitol 2004;57:309-76.

6. Hay RJ, Steer AC, Engelman D, Walton S. Scabies in the developing world-its prevalence, complications, and management. Clin Microbiol Infect 2012; 18.

7. Burkhart CG, Burkhart CN, Burkhart KM. An epidemiologic and therapeutic reassessment of scabies. Cutis 2000;65: 233-40.

8. Andersen LK, Davis MD. The effects of the El Niño Southern Oscillation on skin and skin-related diseases: a message from the International Society of Dermatology Climate Change Task Force. Int J Dermatol 2015;54:1343-51.

9. FDRE. Scabies out break preparedness and Response Plan. In: Health MO, editor. Addis Ababa, Ethiopia 2015.

10. Wochebo W, Haji Y, Asnake S. Scabies outbreak investigation and risk factors in Kechabira district, Southern Ethiopia: unmatched case control study. BMC Res Notes 2019;12.

11. Ejigu K, Haji Y, Toma A, Tadesse BT. Factors associated with scabies outbreaks in primary schools in Ethiopia: a case-control study. Res Rep Trop Med 2019;10:119-27.

12. Cassell JA, Middleton J, Nalabanda A, et al. Scabies outbreaks in ten care homes for elderly people: a prospective study of clinical features, epidemiology, and treatment outcomes. Lancet Infect Dis 2018;18:894-902.
13. Jarso S, Haji Y, Gebretsadik A. Scabies Outbreak Investigation and Risk Factors in East Badewacho District, Southern Ethiopia: Unmatched Case Control Study. Dermatol Res Prac 2018;0.

14. Nazar M, Azizi A. Epidemiological Pattern of Scabies and Its Social Determinant Factors in West of Iran. Health 2014;6:1972-7.

15. Hegab DS, Kato AM, Kabbash IA, Dabish GM. scabies among primary schoolchildren in egypt: sociomedical environmental study in Kafr el-sheikh administrative area. Clin Cosmet Invest Dermatol 2015;8:105-11.

16. Romani L, Koroivueta J, Stee AC, et al. Scabies and Impetigo Prevalence and Risk Factors in Fiji: A National Survey. PLOS Negl Trop Dis 2015;9:e0003452.

17. Gaspard L, Laffitte E, Michaud M, et al. Scabies in 2012. Rev Med Suisse 2012;8:718-22.

18. Suleman S, Ullah H. Epidemiological study of scabies in district Haripur, Pakistan. Arthropods 2016;5:151-61.

19. Dagne H, Dessie A, Destaw B, et al. Prevalence and associated factors of scabies among schoolchildren in Dabat district, northwest Ethiopia, 2018. Environm Health Prev Med 2019;24.

20. Amhara public health institute (APHI). scabies report. 2017.

21. Chandler DJ, Fuller LC. A Review of Scabies: An Infestation More than Skin Deep. Dermatology 2019;235:79-90.

22. Ohio Department of health. Scabies Prevention and Control Guidelines. 2019. 